\title{
Addendum
}

\section{The growing incidence of prostate cancer in the French Caribbean islands, Martinique and Guadeloupe: A possible causal role of pesticides}

\author{
D. BELPOMME ${ }^{1,2}$, P. IRIGARAY ${ }^{2}$, M. LANDAU-OSSONDO ${ }^{3}$ and M. MARTIN ${ }^{2}$ \\ ${ }^{1}$ Paris V University, Department of Medical Oncology, European Hospital Georges Pompidou (HEGP); ${ }^{2}$ Cancer Research \\ Center, Association for Research and Treatments Against Cancer (ARTAC), F-75015 Paris, France; ${ }^{3}$ Anatomopathology \\ Laboratory, Centre Hospitalier Universitaire de Fort de France, French West Indies, F-97200 Fort de France, Martinique
}

Received May 4, 2009; Accepted May 20, 2009

DOI: 10.3892/ijo_00000356

In a recent paper published in the journal (1), we reported results of an ecological multifactorial study showing that the growing incidence of prostate cancer in Martinique and Guadeloupe is probably caused by environmental factors, and have hypothesized in a second paper that among factors,

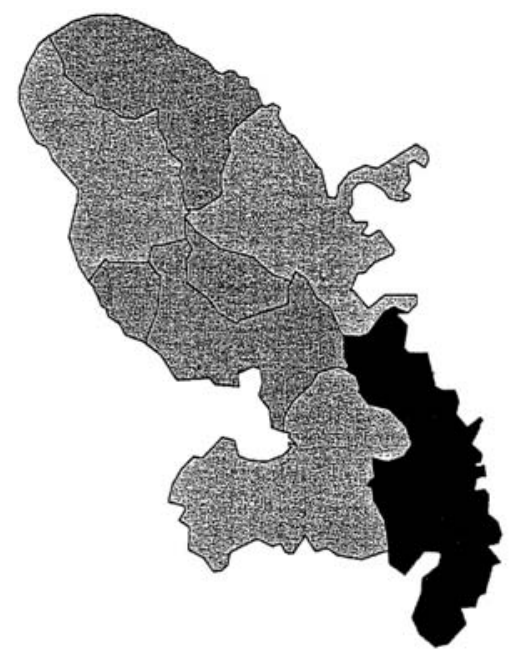

Figure 1. Distribution of standardized incidence ratio (SIR) of prostate cancer (grey and black) $0.85-0.95 ; 0.95-1.05$; (dark grey and black) $>1.15$ according to AMREC. spray of organochlorine pesticides might be causally involved (2). Table I indicates the different carcinogenic, mutagenic and/or reprotoxic (CMR) or presumed CMR pesticides used since 1955 in the two islands. Unlike that indicated in our first paper (1), aldrin and dieldrin are not rated as $2 \mathrm{~B}$ carcinogens but instead as group 3 in the IARC classification. Moreover, although our paper clearly showed an excess of prostate cancer in the South East part of Martinique (Fig. 1), unfortunately in the text, this area was mentioned as corresponding to the South-West of the island. These two necessary precisions do not change the basic conclusions of our paper, and the importance of its scientific message, since it clearly establishes for the first time that prostate cancer may be an environmental disease.

\section{References}

1. Belpomme D, Irigaray P, Ossondo M, Vacque D and Martin M: Prostate cancer as an environmental disease: an ecological study in the French Caribbean islands, Martinique and Guadeloupe. Int J Oncol 34: 1037-1044, 2009.

2. Landau-Ossondo M, Rabia N, Jos-Pelage J, Marquet LM, Isidore Y, Saint-Aimé C, Martin M, Irigaray P and Belpomme D: Why pesticides could be a common cause of prostate and breast cancers in the French Caribbean Island, Martinique. An overview on key mechanisms of pesticide-induced cancer. Biomed Pharmacother (In press).

Table I. CMR and presumed CMR pesticides used since 1955 in Martinique and Guadeloupe.

\begin{tabular}{|c|c|c|c|c|c|}
\hline & On the market & $\begin{array}{l}\text { Maximum } \\
\text { of use }\end{array}$ & $\begin{array}{l}\text { Withdrawal from the market } \\
\text { for agricultural use }\end{array}$ & $\begin{array}{l}\text { Continuation } \\
\text { of use }\end{array}$ & $\begin{array}{c}\text { IARC } \\
\text { classification }\end{array}$ \\
\hline Technical DDT & 1939 & $1960-1990$ & 1972 & & $2 \mathrm{~B}$ \\
\hline Technical HCH & $1940^{\mathrm{a}}$ & $1950-1960$ & 1988 & 1998 & $2 \mathrm{~B}$ \\
\hline Lindane & $1940^{\mathrm{a}}$ & $1950-1960$ & 1992 & & $2 \mathrm{~B}$ \\
\hline Aldrin/dieldrin & $1950^{\mathrm{a}}$ & 1960 & 1972 & 1992 & 3 \\
\hline Chlordecone & 1972 & 1980 & 1990 & 1993 & $2 \mathrm{~B}$ \\
\hline Chlordanes & $1960^{\mathrm{a}}$ & & & & $2 \mathrm{~B}$ \\
\hline Perchlordecone (mirex) & $1977^{\mathrm{a}}$ & 1980 & 1990 & & $2 \mathrm{~B}$ \\
\hline Simazine & $1991^{\mathrm{a}}$ & & 2001 & & $3^{\mathrm{b}}$ \\
\hline
\end{tabular}

${ }^{a}$ Official data not available. ${ }^{b}$ Simazine, a non-organochlorinated molecule, is associated with an increased risk of prostate cancer. Technical

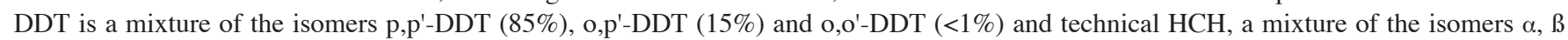
and $\gamma$. Chlordanes include trans-chlordane, cis-chlordane, trans-nonachlor, cis-nonachlor and heptachlor. 